\title{
Clinical Reasoning: A 53-year-old woman with lower extremity paresthesias
}

Sara Dehbashi, MD, Peter Jin, MD, Donald Edelschick, MD, and Susan Shin, MD

Neurology ${ }^{\circledR}$ 2020;94:1105-1108. doi:10.1212/WNL.0000000000009645
Correspondence

Dr. Shin

susan.shin@mssm.edu

\section{Section 1}

A 53-year-old woman with no relevant medical history presented to our clinic for evaluation of lower extremity paresthesias. She initially felt an intermittent tingling sensation in the feet, which slowly crept up both legs and became more intense and constant over 6 months. She noted that these sensations seemed to stop abruptly at her waist. Similar paresthesias were felt in her left arm but not as pronounced as in her legs. She denied any gait imbalance or weakness.

Physical examination demonstrated pes cavus foot deformity. Limb strength and deep tendon reflexes were normal throughout. Sensory testing of vibration, pinprick, light touch, and joint position sense was normal throughout. Contrary to the patient's complaints, a sensory level was not found. The patient noted that both her mother and sister have high arched feet, but she denied any family history of any neuromuscular disorders.

\section{Questions for consideration:}

1. What is the localization for her presentation?

2. What are the differential diagnoses?

GO TO SECTION 2 


\section{Section 2}

The patient in this vignette presented with pure sensory symptoms progressing over several months. At this point, the differential diagnosis is broad, as the patient's symptoms are nonspecific and both central and peripheral localizations can result in such presentation. The prominent sensory symptoms in the legs with abrupt termination at her waist could be localized to the spinal cord such as in degenerative spine disease, transverse myelitis, or even a CNS demyelinating disease involving both the brain and spine. The remainder of the history and examination, however, make these diagnoses unlikely: normal reflexes make spinal cord pathology in general an unlikely diagnosis, a pure sensory syndrome would be rare in transverse myelitis as it affects a cross-section of the spinal cord, and there are no findings suggesting brain or brainstem involvement. Slowly progressive and ascending sensory symptoms with an absence of findings suggestive of myelopathy is more suggestive of a peripheral process such as sensory polyneuropathy.

The differential for polyneuropathy can be divided in multiple ways.
1. Large fiber vs small fiber: Typically large fiber neuropathies demonstrate signs of depressed reflexes, weakness, and diminished vibration and position sense. Small fiber neuropathies, on the other hand, have more minimal examination findings of diminished sensation to sharp and temperature with otherwise normal reflexes and strength.

2. Hereditary vs acquired: Hereditary polyneuropathies generally are associated with a family history of polyneuropathy and can manifest in both childhood and adulthood. A distinctive pes cavus foot appearance can be a diagnostic clue for Charcot-Marie-Tooth hereditary polyneuropathy.

3. Primary vs secondary: Polyneuropathies may occur secondary to a systemic disease (e.g., diabetes, monoclonal gammopathy, toxin) or may be a primary disease (e.g., chronic inflammatory demyelinating polyradiculoneuropathy $[\mathrm{CIDP}])$.

4. Axonal vs demyelinating: Polyneuropathies can be associated with axonal loss (e.g., diabetic polyneuropathy) or demyelination (e.g., CIDP).

\section{Question for consideration:}

1. What investigations can help narrow the differential diagnosis?

GO TO SECTION 3 


\section{Section 3}

Distinction among the various categories of polyneuropathy as outlined above is difficult based on history and examination alone due to the nonspecific presentation of most polyneuropathies. Furthermore, there are innumerable causes of polyneuropathy. This dilemma can lead to nonspecific and extensive (i.e., "shotgun") testing.

In our patient, there were no systemic findings or medical history to suggest a secondary cause of polyneuropathy, and the physical examination findings were minimal. Given the limited data, performing a nerve conduction and needle EMG study is the most helpful test as it can help characterize the potential polyneuropathy and prioritize future studies.

Nerve conduction study demonstrated a widespread demyelinating motor neuropathy without conduction block. For example, the left peroneal compound muscle action potential recorded over the extensor digitorum brevis muscle revealed a distal latency of $3.9 \mathrm{~ms}$, amplitude of $6.1 \mathrm{mV}$, and conduction velocity of $30 \mathrm{~m} / \mathrm{s}$. The left sural sensory amplitude was $11 \mu \mathrm{V}$ and conduction velocity $46 \mathrm{~m} / \mathrm{s}$. The patient's limb temperature was $33^{\circ} \mathrm{C}$. Upper and lower limb motor nerve conduction velocities were in the low 30s with normal onset latency and compound muscle action potential amplitudes. Sensory responses were normal, but the sensory nerve action potential amplitude of sural and superficial peroneal nerves was reduced compared to the upper limb sensory nerve amplitudes. Needle EMG of select muscles in the upper and lower limb was normal.

The EMG narrowed the differential to causes of demyelinating neuropathies. The predominant motor involvement brought up the possibility of multifocal motor neuropathy and a motor predominant CIDP; however, the lack of conduction block made an acquired immune inflammatory neuropathy less likely. The uniform demyelinating changes along with the patient's and patient's family's pes cavus foot shape suggest the possibility of Charcot-Marie-Tooth disease (CMT).

Neuromuscular ultrasound was used to evaluate the morphology of the patient's nerves. It showed widespread and uniform increase in the nerves' cross-sectional area and marked enlargement within the nerves' fascicular architecture in the median, ulnar, radial, peroneal, and tibial nerves (figure).

The findings of uniformly slowed conduction velocity without conduction block, ultrasound findings of widespread, uniform nerve enlargement, and pes cavus foot deformity were more suggestive of a hereditary cause of demyelinating neuropathy. This is in contrast to acquired demyelinating neuropathies, which is classically associated with electrophysiologic conduction block along with ultrasound findings of patchy, focal nerve enlargement near the region of conduction block.

Genetic testing for CMT was performed, which identified the pathogenic variant c.331 G>A (p.Ala111Thr) in the LITAF gene, which is associated with autosomal dominant CMT disease type 1C (CMT1C).

Of note, upon discovery of a demyelinating neuropathy on EMG, the patient underwent an extensive series of tests in search for other etiologies of polyneuropathy, all unremarkable. These included a normal MRI of the brain and cervical, thoracic, and lumbar spine. CSF studies were normal. Serum studies were normal, including complete blood count, comprehensive metabolic panel, erythrocyte sedimentation rate, C-reactive protein, vitamin $B_{12}$, vitamin $B_{6}$, folate, immunofixation electrophoresis, serum protein electrophoresis, antinuclear antibodies, angiotensin-converting enzyme, anti SS-A, anti SS-B, Lyme antibody, HIV, hepatitis C, ganglioside panel, and paraneoplastic antibodies. Skin biopsy showed normal distal and proximal epidermal nerve fiber densities.

\section{Discussion}

CMT is the most common hereditary polyneuropathy. It consists of different subtypes that are genetically distinct disorders. The most common subtype is type 1 , a demyelinating peripheral neuropathy, characterized by sensory symptoms and distal muscle weakness often associated with foot drop and pes cavus deformity. The other genetic subtypes of CMT can differ in clinical presentation and electrodiagnostic profile.

CMT1C is a rare dominantly inherited subtype of CMT1, caused by mutations in the LITAF gene (lipopolysaccharideinduced tumor necrosis factor- $\alpha$ factor), also known as SIMPLE (small integral membrane protein of the lysosome/late endosome), on chromosome 16p13.1-p12.3. In a large study of 968 cases of CMT1, the percentage of patients with LITAF mutations was only $0.6 \%{ }^{1}$

Guimarães-Costa et al. ${ }^{2}$ studied 18 patients diagnosed with CMT1C and described 2 groups of patients: CMT-like (11/18 patients), encompassing patients with motor weakness, and the sensory form, consisting of patients with predominantly sensory symptoms or asymptomatic complaints of transient pain in feet or fingers, and repeated ankle sprains, without any motor weakness or gait imbalance. Sensory system examination was abnormal in only 4 patients in the second group (7/18 patients). The mean age at onset was 20 years. Almost all patients had pes cavus. Interestingly, the 2 patients with the same genetic variant as in our case had the CMT-like phenotype; however, our patient presented clinically with the sensory form.

Patient series have shown that motor nerve conduction velocities were significantly lower in patients with CMT1C compared with patients with hereditary neuropathy with liability to pressure palsy, but higher compared with patients with CMT1A. Mean motor nerve conduction velocity of the median nerve was $33 \mathrm{~m} / \mathrm{s}$ in patients with CMT1C. Also in contrast to CMT1A, sensory nerve action potentials may be detectable in all 4 limbs in CMT1C. The 2 phenotypic presentations of 


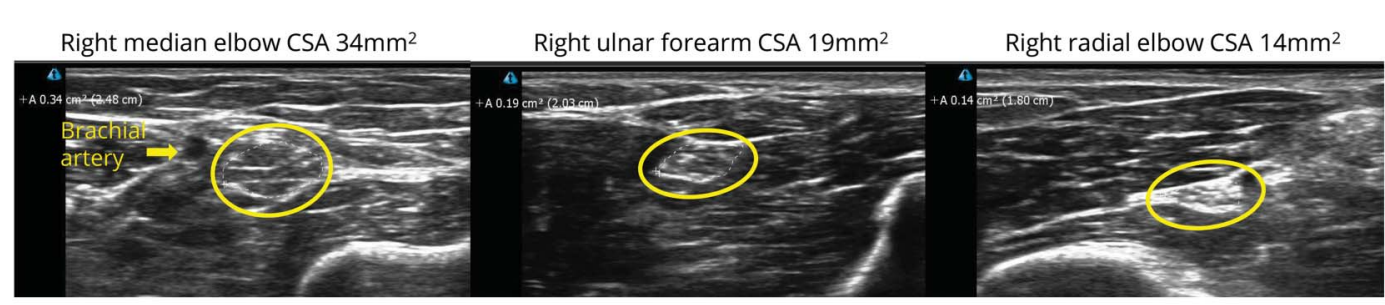

Right peroneal knee CSA $15 \mathrm{~mm}^{2}$

Right tibial knee CSA 56mm²

Right sural ankle CSA $8 \mathrm{~mm}^{2}$

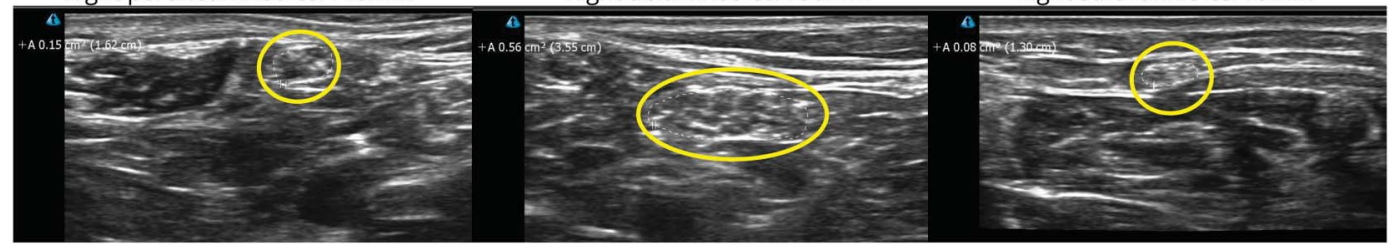

CMT1C do not seem to be differentiated in electrodiagnostic studies. Although not frequently present, some studies have also reported temporal dispersion of nerve conduction, irregularity of conduction slowing, conduction blocks, and even an axonal pattern in some patients. ${ }^{3-5}$

Neuromuscular ultrasound can be useful as a supplemental study in these patients to help distinguish between acquired and hereditary forms of demyelinating neuropathy. Typically in hereditary neuropathies such as CMT1A, ultrasound reveals uniform and diffuse increased cross-sectional area in most nerves tested. ${ }^{6,7}$ This is in contrast to patients with acquired demyelinating neuropathies, who demonstrate patchy and focal enlargements of cross-sectional area along the nerve. This distinction can be difficult as more advanced cases of acquired demyelinating neuropathies can affect the cross-sectional area of the entire nerve. In our case, the findings of minimal examination findings, uniform slowing on motor nerve studies, an absence of conduction block, and a uniform enlargement of cross-sectional area of peripheral nerves all supported a diagnosis of a hereditary neuropathy over an acquired neuropathy such as an atypical variant of CIDP.

This case represents an example of polyneuropathy that presented with minimal clinical findings and subsequently demonstrated very striking electrodiagnostic and sonographic findings that ultimately prompted diagnostic genetic testing. The combination of minimal examination findings with striking and uniform slowing of conduction velocities with an absence of conduction block or temporal dispersion should prompt consideration for a hereditary demyelinating neuropathy over an acquired demyelinating neuropathy. Ultrasound findings can correlate with this distinction, as patterns of nerve cross-sectional area enlargement frequently present uniformly in hereditary cases and are patchier in acquired cases. As mentioned previously, extensive testing for other causes of polyneuropathy and other localizations were performed and were ultimately fruitless. This case highlights the importance and utility of synthesizing the data from clinical, imaging, and electrodiagnostic studies in cases of suspected polyneuropathy to narrow testing for potential etiologies.

\section{Study funding}

No targeted funding reported.

\section{Disclosure}

The authors report no relevant disclosures. Go to Neurology. org/ $\mathrm{N}$ for full disclosures.

Appendix Authors

\begin{tabular}{lll}
\hline Name & Location & Contribution \\
\hline $\begin{array}{l}\text { Sara } \\
\text { Dehbashi, } \\
\text { MD }\end{array}$ & $\begin{array}{l}\text { Jefferson University } \\
\text { Hospitals }\end{array}$ & $\begin{array}{l}\text { Manuscript drafting/revision, } \\
\text { literature review }\end{array}$ \\
\hline $\begin{array}{l}\text { Peter Jin, } \\
\text { MD }\end{array}$ & $\begin{array}{l}\text { University of } \\
\text { Maryland School of } \\
\text { Medicine }\end{array}$ & $\begin{array}{l}\text { Manuscript drafting/revision, } \\
\text { literature review }\end{array}$ \\
\hline $\begin{array}{l}\text { Donald } \\
\text { Edelschick, } \\
\text { MD }\end{array}$ & $\begin{array}{l}\text { Private practice, } \\
\text { New York }\end{array}$ & $\begin{array}{l}\text { Referred patient, critically reviewed } \\
\text { the manuscript }\end{array}$ \\
\hline $\begin{array}{l}\text { Susan Shin, } \\
\text { MD }\end{array}$ & $\begin{array}{l}\text { Icahn School of } \\
\text { Medicine at Mount } \\
\text { Sinai }\end{array}$ & $\begin{array}{l}\text { Critical revision of the manuscript } \\
\text { for important intellectual content, } \\
\text { contribution of ultrasound data, } \\
\text { analysis and interpretation of data, } \\
\text { study supervision }\end{array}$ \\
\hline
\end{tabular}

\section{References}

1. Latour P, Gonnaud PM, Ollagnon E, et al. SIMPLE mutation analysis in dominant demyelinating Charcot-Marie-Tooth disease: three novel mutations. J Peripher Nerv Syst 2006;11:148-155.

2. Costa R, Iancu Ferfoglia R, Leonard-Louis S, et al. Phenotypic spectrum of CharcotMarie-Tooth disease due to LITAF/SIMPLE mutations: a study of 18 patients. Eur J Neurol 2017;24:530-538.

3. Jerath NU, Shy ME. Charcot-Marie-Tooth disease type 1C: clinical and electrophysiological findings for the c.334G >a (p.Gly112Ser) Litaf/Simple mutation. Muscle Nerve 2017;56:1092-1095.

4. Gerding WM, Koetting J, Epplen JT, et al. Hereditary motor and sensory neuropathy caused by a novel mutation in LITAF. Neuromuscul Disord 2009;19:701-703.

5. Ciotti P, Luigetti M, Geroldi A, et al. A novel LITAF/SIMPLE mutation within a family with a demyelinating form of Charcot-Marie-Tooth disease. J Neurol Sci 2014;343:183-186.

6. Luigetti M, Sabatelli M, Bellone E, et al. Nerve ultrasound in patients with CMT1C: description of 3 cases. Muscle Nerve 2015;51:781-782.

7. Cartwright MS, Brown ME, Eulitt P, Walker FO, Lawson VH, Caress JB. Diagnostic nerve ultrasound in Charcot-Marie-Tooth disease type 1B. Muscle Nerve 2009;40: 98-102. 


\section{Neurology}

\section{Clinical Reasoning: A 53-year-old woman with lower extremity paresthesias}

Sara Dehbashi, Peter Jin, Donald Edelschick, et al.

Neurology 2020;94;1105-1108 Published Online before print May 27, 2020

DOI 10.1212/WNL.0000000000009645

This information is current as of May 27, 2020

Updated Information \&
Services

References

Subspecialty Collections

Permissions \& Licensing

Reprints including high resolution figures, can be found at: http://n.neurology.org/content/94/24/1105.full

This article cites 7 articles, 0 of which you can access for free at: http://n.neurology.org/content/94/24/1105.full\#ref-list-1

This article, along with others on similar topics, appears in the following collection(s):

All Genetics

http://n.neurology.org/cgi/collection/all_genetics

All Neuromuscular Disease

http://n.neurology.org/cgi/collection/all_neuromuscular_disease

Peripheral neuropathy

http://n.neurology.org/cgi/collection/peripheral_neuropathy

Ultrasound

http://n.neurology.org/cgi/collection/ultrasound

Information about reproducing this article in parts (figures,tables) or in its entirety can be found online at:

http://www.neurology.org/about/about_the_journal\#permissions

Information about ordering reprints can be found online:

http://n.neurology.org/subscribers/advertise

Neurology ${ }^{\circledR}$ is the official journal of the American Academy of Neurology. Published continuously since 1951, it is now a weekly with 48 issues per year. Copyright () 2020 American Academy of Neurology. All rights reserved. Print ISSN: 0028-3878. Online ISSN: 1526-632X.

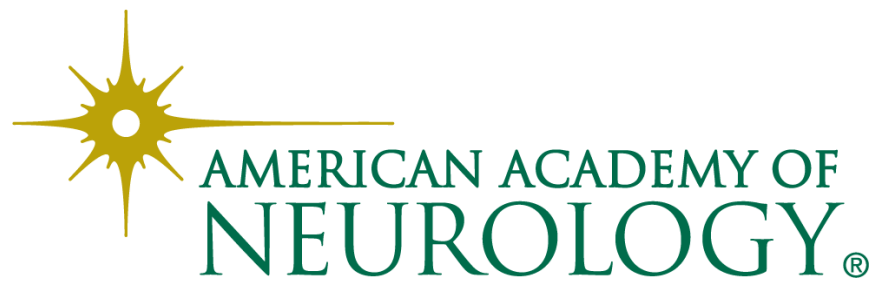

